HoST - Journal of History of Science and Technology

Vol. 14, no. 1, June 2020, pp. 79-112

10.2478/host-2020-0005

SPECIAL ISSUE

STANDARDS: TAMING KNOWLEDGE?

\title{
Preserved Worlds: Vulnerability, Ontology, and the Logics of Standards
}

\author{
Nuria Valverde-Pérez \\ Universidad Autónoma Metropolitana, México \\ nvalverdep@protonmail.com
}

\begin{abstract}
Standards are linked to specifications about scaling, safety, feasibility and suitability. The threshold setting process defines the environment in which the standards are meaningful to a given community and the conditions of vulnerability implied by their absence. This paper will discuss the role of standards in defining safety conditions for endangered bird species in urban environments and in designing closed environments for polio patients during the 1950s, the infamous iron lungs, which are still rarely used today. The aim is to explore how standards are involved in defining preservation strategies and the shortcomings of their systematic implementation in this regard. The interdependence of technological standards and the increasing amount of information handled are joining cultural assemblages to question the objectives of preservation in artificial environments, urging the question of what we are preserving. This raises the issue of the relationship between stabilisations through epistemic tools and ontological continuity and robustness in dense technological environments.
\end{abstract}

Keywords: Ontological (dis)continuity; preservation; liminality; history of science; philosophy of technology; iron-lungs; bird sonic niche; techno-epistemic stabilisation 


\section{Introduction: Specifications for Environments, Thresholds, and Vulnerability}

Both in the human and animal kingdoms, life-saving intervention is often linked with different types of enclosure. Specific spaces are designed to preserve fragile states of living that would not otherwise survive the threat posed by agents of excess or precarity. Whether these synthetic environments imply an "exoskeletal" enclosure or not, reproducing the exact conditions of ex-situ or in-situ environments that have already been lost to change involves a more complex set of problems than their often deceptively-simple solutions might suggest. This strategy is not entirely new, as the history of greenhouses attests.

One difficulty is that artificial environments, no less than "natural" ones, shape the relationships between the beings involved, altering the notions that these creatures may have of one another. And yet, preservation aims precisely at the contrary: a suspension of transformation, a controlled existence in which the qualities and capabilities displayed by the target entity are non-accidental, authentic, and inherent to it. This is what makes preservation a fundamentally ontological project. But what seems to be paradoxical is that the entire enterprise of preservation is embedded in a transformative, dynamic world. This means that transformation is consubstantial to all the entities that take part of this world, and that changes in them also produce changes in their environment. Change control is problematic, often untenable, and so it is not easy to carefully pick up the kind of entities one wants to relate to, and to exclude others - whether by motives of convenience, security, or proximityadditionally it entails serious ethical problems. ${ }^{1}$

Things change in two fundamental ways: they stop to affect other things in an expected and sustained way, or they plastically adapt to the environment, that is, to a set of new elements that affects them (asymmetrically or not). But change has a limit in dissolution. The kind of flows, inherent forces and interactions that prevent the dissolution of things or even produce them (ontogenesis) has been a main concern in contemporary philosophy from different

\footnotetext{
${ }^{1}$ Judith Butler, "Precarious Life, Vulnerability, and the Ethics of Cohabitation," Journal of Speculative Philosophy 26, no. 2 (2012): 134-151.
} 
approaches. ${ }^{2}$ Especially when we talk about complex techno-social systems, negentropic and transductive dynamics play a special role in explaining how things relate to their environment producing more or less stable (trans)individuals ${ }^{3}$ or "machines." ${ }^{4}$ Standards—as well as laws, formulas, protocols_-are part of these negentropic forces that sustain what Deleuze and Guattari called the striated space that characterise Estate organisations, the space that is organised, measured, and compartmentalised under strict communication rules. Embedded in infrastructure and cultural practices, standards can be considered "incorporeal machines" 5 that guarantee appropriate connection or coupling between (sets of) things, thus sustaining the orders and synergies or assemblages that hold a specific cultural, political, and material world. Science and technology studies have paid attention to the different ways in which the development of infrastructures and technologies involved in specific enactments of practices and material possibilities gives place to empirical ontologies, whether these are considered from a relational materialist, multiple and fluid perspective of identity, ${ }^{6}$ or from the stabilisation of empirical differences by sustained practices. ${ }^{7}$ As Bryant puts it, any machine- organic or notis, due its inherent limitations, blind to part of the world, ${ }^{8}$ so bias is a feature of anything that has a shape, a definition; but whenever standards and technological design are present, bias takes the form of an alarm regarding the exceeding of the thresholds. The vulnerability of the objects involved takes the form of powerlessness to change. The consequence, as we shall see, is selective blindness towards change and, hence, political invisibilisation of relevant affections/ reactions between things that demand new configurations or in-formations of themselves.

2 One of the most pervasive scientific influences in the philosophical realm is Jakob Johann von Uexküll, Theoretical Biology (London: Kegan Paul, Trench, Trubner \& Co., 1926), which influenced Martin Heidegger, Los conceptos fundamentales de la metafisica. Mundo, finitud y soledad (Madrid: Alianza Editorial, [1930] 2007); Georges Canguilhem, Knowledge of Life (New York: Fordham University Press, [1952] 2008); Gilbert Simondon, L'individuation à la lumière des notions de forme et d'information (Grenoble, France: Millon, [1958] 2013); and Gilles Deleuze and Félix Guattari, $A$ Thousand Plateaus. Capitalism and Schizophrenia (Minneapolis: University of Minnesota Press, [1980] 2005). For an overview of his influence, see Brett Buchanan, Onto-ethologies: The Animal Environment of Uexküll, Heidegger, Merleau-Ponty, and Deleuze (New York: SUNY, 2009). More deeply cultural and technological notions of environment, and hence of the interweaving of technologies and anthropology, or technogenesis and ontogenesis were developed by André Leroi-Gourhan, Le geste et la parole.vol.1 Technique et langage (Paris: Albin Michel, 1964), an important reference for Bruno Latour, John Law, and the Actor-Network Theory in general.

${ }^{3}$ Simondon, L'individuation.

${ }^{4}$ Deleuze and Guattari, A Thousand Plateaus, passim.

5 Levi R. Bryant, Onto-Cartography. An Ontology of Machines and Media (Edinburgh: Edinburgh University Press, 2014), 26-27.

6 See Annemarie Mol, "Mind your plate! The ontonorms of Dutch dieting," Social Studies of Science 43, no. 3 (2013): 379-396; Bernadette Bensaude-Vincent, "Philosophy of Chemistry or Philosophy with Chemistry?" HYLE--International Journal for Philosophy of Chemistry 20, no. 1 (2014): 58-76.

7 See John Law, and Marianne E. Lien, "Slippery: Field notes in empirical ontology," Social Studies of Science 43, no. 3 (2013): 363-378.

${ }^{8}$ Bryant, Onto-Cartography, 59. 
Standards, as any other machine, have their own ontogenetic process - this is what historical ontology is about. ${ }^{9}$ They do have to match not just other cultural machines, but also strong material limits and possibilities, since, as said, they always are incarnated in some device or material procedure. ${ }^{10}$ And, crucially, they articulate compounds of expectations, which are the basis of technological innovation. Expectations relate to an imposed history—as Deleuze and Guattari suggest ${ }^{11}$ - that is not just imposed by humans, but also by non-humans. Expectations define the enactment of agents' relevant potentialities for a specific assemblage: a fertilised egg is expected to hatch within a specific range of sustained temperature whether the heat source is a bird or a power-driven system. And this definition is instilled by standards that also stipulate the type and range of the relations that would guarantee a result. In this way, the material dimension of being/becoming and the potentialities of doing/functioning are restricted to a planned setting, with no room for vagaries, whims, or pastiche. By tightly harnessing specific type of relations between specific things, standards often confound expression and content. Relations between content and expression, code and territorialisation (Deleuze \& Guattari), information and amplification (Simondon), vary according to the compensation of changes. Understanding the type of relationships that operate in these cases calls for maps, ontographies $^{12}$ and onto-cartographies that challenge not only homogeneous notions of time and space, but the dissolution of a constant and mutually (re)constructive tension between the two terms.

To approach an analysis of standards from this perspective in terms of their involvement in preservation spaces is to place it on a hinge. When standards are used to manage a preservation space, they become trapped in a contradiction: they struggle to maintain a (fire)wall with an active environment, and in doing this, not only do they forget the inherent forces that drive the emergence of alternative assemblages or object combinations, or the fact that entities are not entirely determined by taxonomies, phylogenetic links, or by normative constrictions, but also by ways of inhabiting a space. They also manifest the failure of their own specifications to hold the world they are intending to protect or control. The subtle distance between expression and content reopens, and standards efforts to harness time, function and identity within these spaces correlate to ways of becoming that challenge the same practices that give rise to them. ${ }^{13}$

\footnotetext{
9 Ian Hacking, Historical Ontology (Cambridge, Mass.: Harvard University Press, 2002).

${ }^{10}$ For a thorough analysis in both respects, see Davis Baird, Think Knowledge. A Philosophy of Scientific Instruments (Berkeley \& Los Angeles: University of California Press, 2004); Tim Ingold, "Materials against materiality," Archaeological Dialogues 14 (2007): 1-16.

${ }^{11}$ Deleuze and Guattari, $A$ Thousand Plateaus, 276.

12 Ontographies represent an epistemological approach to onto-cartographies. See Michael Lynch, "Ontography: Investigating the production of things, deflating ontology," Social Studies of Science 43, no. 3 (2013): 444-462. On onto-cartographies see Bryant, Onto-Cartography.

13 This would explain why totalitarian regimes look, according to Bryant, more "fragile" than "loosely organized ecologies." Bryant, Onto-Cartography, 152.
} 
Paradoxically, then, systematic implementation of standards in the cases of preservation entails, as we will see, their own obsolescence. In this sense, the rationality that depends on calculation and anticipation finds its own limits. Not just as a reaction to its rigidity, as Bryant argues. ${ }^{14}$ The efforts of the standards to maintain the reins of the scaling of innovation while attempting to keep control of a transforming environment produce a nesting of standards that poses unsurmountable challenges to time and space managing.

Producing a segregated space is a way of making ontological statements and exploring the nature of time, autonomy, and change. Liminal spaces emerged in the eighteenth-century as a problem related to the activity of potentially dangerous agents and precautionary and hygienic policies, ${ }^{15}$ and they became a constant feature of modernity. ${ }^{16}$ They are used to maintain an environmental status quo whereas preserving a dangerous energy reservoir-whether it be considered as a political, cultural, physic or biological force-, which highlights its inherent ambiguity as spaces of preservation and control. ${ }^{17}$ But technological development has made them increasingly more conspicuous as "suspended spaces," sites where neither regular timeas in the case of cryogenisation ${ }^{18}$ - nor regular behaviour nor regular order occur.

Moreover, synthetic environments are understood to provide "an external point of comparison and the operationalised increments to standardise difference." 19 That is, they are expected to provide a more accurate measurement that allows to control both the ontological features of the individuals comprised in them, and the relevant and stable differences between them. How much can the environment be considered "external," even in these cases, is a matter for debate. Likewise, the correct understanding of the term "standardised difference" also poses a problem: if standards highlight relevant features for sustaining a machine or assemblage, they do so by articulating and instilling expectations, so what is this difference about? How is time and material, morphological change managed when these expectations about operations and processes are projected towards new environments? In which sense can technology coproduce

\footnotetext{
14 Bryant, Onto-Cartography, 152.

${ }^{15}$ Nuria Valverde, "A line of touch: Liminality and environment in eighteenth-century Spanish Empire," in The Routledge Companion to the Hispanic Enlightenment, eds. Elizabeth Franklin Lewis, Mónica Bolufer, and Catherine M. Jaffe, 43-56 (London \& New York: Routledge, 2020).

${ }_{16}$ Bjørn Thomassen, Liminality and the Modern: Living Through the In-between (London \& New York: Routledge, 2016).

17 Think, for example, of the long and contended existence of refugee camps.

18 See Joanna Radin and Emma Kowal, eds., Cryopolitics: frozen life in a melting world (Cambridge, Mass.: MIT Press, 2017); Alexander Friedrich and Stefan Höhne, "Regimes of freshness. Biopolitics in the age of cryogenic culture," Medicine Anthropology Theory 3, no. 3 (2016): 112-154.

${ }^{19}$ Jeffrey West Kirkwood and Leif Weatherby, "Introduction. The Culture of Operations: Ernst Kapp's Philosophy of Technology," in Elements of a Philosophy of Technology by Ernst Kapp, trans. by Lauren K. Wolfe, eds. Jeffrey West Kirkwood and Leif Weatherby, ix-xliii (Minneapolis: University of Minnesota Press, 2018), xxx.
} 
the essential difference between two entities? When these questions are posed in the midst of concerns about preservation and within the context of a rhetoric of extinction and precariousness, it becomes all the more urgent to analyse how these differences emerge in our attempts to produce ontological continuity between what we can expect to preserve and what is produced by a dynamic process of individuation. ${ }^{20}$

When segregation, understood as the artificial production of a suitable proxy environment for specific types of beings, takes place in a dense technological environment and as a consequence of it, as new relationships and interactions begin to take place, underlying questions about our political choices, about the kind of "we" and the kind of "they" instilled in our technological projections, ${ }^{21}$ begin to emerge. Things do not only "withdraw" from relationship in the sense that no description of the flows and connections that make them work can give full account of their absolute unity, as Harman argues; ${ }^{22}$ things also move towards other things. This way they expose themselves to others and make themselves vulnerable to others. It is this being (self-) exposed to unexpected change and intervention-either by the deprivation of a presence or the introduction of a new one-what constitutes the possibility of extensive, non-exclusionary and heterogenous life and cohabitation. ${ }^{23}$ This makes the discussion about preservation and the limits and ways of (self-) preservation particularly relevant.

Thus, this paper explores how environments of preservation have been thought-out in recent times. How have these environments become caught up in narratives of vulnerability, and what does this entanglement imply for the entities subjected to preservation? We must increase our understanding of how soft tools or "incorporeal machines" — as forms, or thresholds_produce standardised differences within a class of beings, and we must recognise how these differences are dependent upon the standardised procedures that are applied across classes more generally. To improve our insight, we must compare how these factors function in relation to different kinds of beings. It is essential to clarify how we use artificial environments to make decisions concerning questions of inter-species vulnerability that force us to make upsetting moral choices. It is also important to remind ourselves that the methodologies of standardisation

\footnotetext{
${ }^{20}$ Diego Lawler and Andrés Vaccari have enlightened this question from an epistemological perspective in their work about the limits of intentionality in the definition of bio-artefacts. They point out to the processes of de-localisation and re-localisation as an important reductionist mechanism. I am grateful to an anonymous reviewer for drawing my attention to this text. Diego Lawler and Andrés Vaccari, "Epistemologia de lo artificial y tipos de artefactos," in Aproximaciones interdisciplinares a la bioartefactualidad, eds. Jorge. E. Linares and Elena Arriaga, 55-78 (México: UNAM, 2016), accessed May 18, 2020, http://www.iisue.unam.mx/investigacion/textos/capitulo_161.pdf

${ }^{21}$ Bernard Stiegler, "The theater of individuation: Phase-shift and resolution in Simondon and Heidegger," Parrhesia 7 (2009): 46-57.

${ }^{22}$ Graham Harman, Tool-Being. Heidegger and the Metaphysics of Objects (Chicago: Open Court, 2002), 222.

${ }^{23}$ See Butler, "Precarious life."
} 
hinge upon notions of included exclusion that are in themselves highly problematic. ${ }^{24}$ They do not, however, necessarily end in the production of docile bodies, either in the foreground or in environmental background.

It is also important to pay attention to the emergent aspects of standardisation in these contexts. Specifications are not just "the particular qualities prescribed for a product or a specimen," and hence they do not only create a class of things. By trying to diminish ambiguity and uncertainty, they also shape socio-material conditions. Conversely, it is precisely because they are also exposed to the instability of their material and cultural environments, the resulting classes of objects are ethically and ontologically unstable. This, in no way implies a failure of the standards, especially if we consider that they are oriented towards the production of differences within a framework. Nonetheless, exploring this instability allows for a better understanding of the technological "path dependence" or lineage dependence that affects its implementation, as well as the tensions and distortions that affect institutional ecologies.

The choice of cases in this paper is not fortuitous. They share a matrix of conceptual infrastructure. Endangerment, preservation of life, precariousness, and liminality are all expressions associated with the types of artificial environments I intend to discuss. A series of material and agency combinations enable these concepts and allow them to dictate guidelines or recommendations for political action. Standards and thresholds provide the opportunity to fix gaps or to deal with unexpected problems by changing modularly. However, the amount of time needed to enact such modular changes, as well as the dynamics behind them, are highly variable. ${ }^{25}$ Following a pattern to implement preservation technology, for example, by establishing a series of thresholds to distribute the use of resources like space, medical funding, bandwidth, and attention, does not necessarily guarantee similar results. Moreover, the consequences might be incongruous at times. At a time when infrastructures appear at their most fragile-just as the environment, likewise, seems to be at its most endangered-the identity of the processes to determine risk hierarchies and safety protocols remains worryingly unclear. To what degree is the existence of techno-human stability, such as adaptation to the iron lung, a cause for concern? Is the stability attained by birds in a highly polluted environment like Chernobyl satisfactory? What, precisely, is at stake in the ontological differentiation produced through standardised measurements?

In the following analysis, I will attempt to capture the nuances and small shifts of the technological adjustment and conceptual redefinition that occurred in the pursuit of a more precise management of information, infrastructure, and resources in two cases: the use of

${ }^{24}$ See Giorgio Agamben, Homo Sacer: Sovereign Power and Bare Life (Stanford, Cal.: Stanford University Press, 1998), 12, 20-23.

25 Susan Leigh Star, "This is Not a Boundary Object: Reflections on the Origin of a Concept," Science, Technology, \& Human Values 35, no. 5 (2010): 601-617, on 611. 
sound recording instruments in the preservation of urban birds diversity, and the preservation of life in iron lungs. To conclude, I shall explore how the dynamics displayed in each case contributed to new notions of environment as ontological niche.

\section{"Are You there?": Urban Birds and the Standardisation of Cohabitation}

"Are you there?" This is a relevant question regarding birds in urban contexts, especially if one lives in densely populated cities or near high-traffic environments. Noise, and not merely chemical contaminants as Rachel Carson feared, has silenced birds. In Mexico City (CDMX), it remains possible to see fragile, graceful tortolitas (Columba Inca), palomas huilotas (Zenaida macroura), zanates (Quiscalus mexicanus) and jumping sparrows with relative ease. You may also catch sight of a hummingbird, but other urban birds categorised as "common" within the city — like finches or swallows - are becoming increasingly difficult to observe and hear. Extensive zones of the city now reach "unacceptable" levels of noise, with some areas attaining consistent levels of noise beyond $60 \mathrm{~dB} \cdot{ }^{26}$

Such noisy soundscapes cause the relationships between animal species and between animals and humans to change in unexpected ways. Due to the increase in noise, birds-one of the affected populations-have serious trouble in preserving the "active space" of their songs and signals, that is, the distance over which the sounds they produce can be heard. ${ }^{27}$ This compromises their physiological health, reproductive success, and species diversity, as well as the structure of their communities. ${ }^{28}$ Unlike humans, however, birds' auditory capabilities and sensitivities can be different from one species to another. ${ }^{29}$ Depending on the range of its species' singing frequency or bandwidth, a bird may be affected by a background noise of $60 \mathrm{~dB}$, for example. Low frequencies are more affected by background noise, while high frequencies are disturbed by the barriers and reflections caused by buildings. Thus, the effect of high levels of noise increases as the species-typical minimum frequencies become lower. Likewise, species with the highest species-typical maximum frequency are more affected by impervious architectural barriers. ${ }^{30}$ Many species cannot overcome this noise or are less

\footnotetext{
${ }^{26}$ Fausto E. Rodriguez Manzo and Elisa Garay Vargas, "Mapa de ruido de la Ciudad de México" (paper presented at the $8^{\circ}$ Seminario de Urbanismo Internacional, Ciudad de México, April 17, 2012).

${ }^{27}$ Jenélle L. Dowling, David A. Luther, and Peter P. Marra, "Comparative effects of urban development and anthropogenic noise on bird songs," Behavioral Ecology 23, no. 1 (2011): 201-209.

${ }^{28}$ Robert J. Dooling and Sandra H. Blumenrath, "Avian Sound Perception in Noise," in Animal Communication and Noise, ed. Henrik Brumm, 229-250, vol. 2, of Animal Signals and Communication book series (Berlin; Heilderberg: Springer-Verlag, 2013), 230.

${ }^{29}$ Dooling and Blumenrath, "Avian Sound," 230.

${ }^{30}$ Dowling, Luther, and Marra, "Comparative effects," 4.
} 
adapted to recognise degraded songs, hence are unable to breed next to continuous high anthropogenic noise. ${ }^{31}$ Therefore, some species are more at risk than others in a loud, urban environment, awakening in us feelings of compassion and urgency, and raising questions about the alleged sustainability of the urban design of compact cities.

However, birds are also adaptive and plastic; their species will follow different strategies to cope with noise, such as changing the frequency and/or amplitude of their sounds, increasing night bird-singing, and fighting for dominance of the sound spectrum. In the case of the house finch (pinzón mexicano / Haemohorus mexicanus, previously Carpodacus mexicanus), whose frequency mean range stretches from $2221 \pm 31.30 \mathrm{~Hz}$ to $5873 \pm 103.42 \mathrm{~Hz}$, it will raise its minimum low-frequency level, but not the maximum high frequency. The song will thus be compressed, and the syllable pitch will change, but not the syllable type. ${ }^{32}$ Some of these changes are only short-term reactions to noise, whereas others become permanent.

There is nothing unnatural about noise. Birds in the wild cohabitate with abiotic (wind, waterfalls) and biotic noise (other birds) that have the potential to mask their singing. The levels of noise in a forest or rainforest can reach an average of $48 \mathrm{~dB}$ and a peak of 56 $\mathrm{dB} .{ }^{33}$ The screaming piha (Lipaugus vociferans) uses calls as loud as $110 \mathrm{~dB}$, and many other species can reach $85-90 \mathrm{~dB} .{ }^{34}$ Certainly, as noise levels approach $85 \mathrm{~dB}$, song production declines and often ceases completely, ${ }^{35}$ but below this point, it is part of their existence and evolution. Human interest in these changes is, however, quite new. The moral burden of being compromising the future of birds-more than any regret we might feel concerning the loss of a relationship built on attentive listening to them-has spurred participation in the monitoring and recording of urban avian specimens. This exploration focuses on the crucial role of noise in the environments that birds share with humans.

Anthropogenic noise has increased at the same pace as the development of cheaper, globallydistributed sound recording artefacts. Consequently, automatic recording and its delicacies toward precise zoological classification is developing at the exact time when birds are increasingly pressed to adjust their communicative patters. This is pivotal for understanding how standardisation works to answer the question that opens this section, thus producing

\footnotetext{
${ }^{31}$ Hans Slabbekoorn, "Singing in the wild: the ecology of birdsong," in Nature's Music. The Science of Birdsong, eds. Peter Marler and Hans Slabbekoorn, 178-205 (San Diego, Cal.: Elsevier Academic Press, 2004), 183, 192.

32 Eira Bermúdez-Cuamatzin, Alejandro Ariel Ríos-Chélen, Diego Gil, and Constantino Macías Garcia, "Strategies of Song Adaptation to Urban Noise in the House Finch: Syllable Pitch Plasticity or Differential Syllable Use?” Behaviour 146, no. 9 (2009):1269-1286, on 1278-79.

${ }^{33}$ Henrik Brumm and Sue Anne Zollinger, "Avian Vocal Production in Noise," in Brumm, Animal Communication and Noise, 187-227, 191.

${ }^{34}$ Ibid.

${ }^{35}$ Ibid., 200.
} 
ontological presence and absence. It is amidst these technological and dense material environments that bio-ontologies - with their attached taxonomies, rules of preservation and fears of extinction, defined thresholds of noise, urban density, pollution-struggle to sustain political and affective relations, or cohabitation, with birds in urban sites. Even though experiential, personal interaction is almost absent.

Technology has entered this space to re-articulate the human-bird relationship, as well as to redefine what are adequate environments and robust, non-precarious existences. The specific technology I want to analyse here is automatic bird identification. Such technology has evolved towards a particular way of producing specifications to establish the typical bird of a species. Let us first summarise briefly how the recording and symbolic identification of birds has changed following a series of lineages of standardisations.

\section{Decoding Birds and Defining Sound Environments}

The introduction of the sound spectrograph in the 1950s broke with a tradition that linked ornithological observation with the aesthetic appreciation of birds through the valuation of plumage and trill from an emotional and mnemotechnic perspective. ${ }^{36}$ Most early technologies for bird-song transcription—-beginning with Garstang's "bird words" — ${ }^{37}$ were accompanied by a sense of failure, mismatch, and by the feeling that much had been omitted from the picture. Nonetheless, once the sound spectrograph began to be manufactured and marketed by the Kay Electric Company under the commercial name of Sona-Graph, naturalists, and ethologists like William H. Thorpe (1902-1986) embraced it enthusiastically. This was because "it enables one to compare by eye side by side the sounds produced by different individuals and different species. [...] The sounds are as it were "crystallised" on paper and a new method of precise approach to certain aspects of bird behaviour has been opened." ${ }^{38}$ In allowing for comparison, the spectrograph increased the diversity of birds: it gave birds a more clearly identifiable grammar and code, articulation and discreteness, and so was allegedly a

\footnotetext{
${ }^{36}$ Rachel Mundy, "Bird song and the Image of Evolution," Society and Animals 17, no. 3 (2009): 206223.

${ }^{37}$ John Bevis, Aaaaw to Zzzzzd: The Words of Birds. North America, Britain, and northern Europe (Cambridge, Mass.; MIT Press, 2010).

${ }^{38}$ William H. Thorpe, "The learning of song patterns by birds, with especial reference to the song of the Chaffinch Fringilla coelebs," Ibis 100 (1958): 535-570, on 543.
} 
better tool for distinguishing between species. ${ }^{39}$ However, a dense technological environmentdescribed by Thorpe in three tight pages - was required for recording, both in the field and in operating the Sona-Graph. The "crystallisation" was a reification of singing that hinged on a pre-defined, depurated recording structure.

The sound spectrograph was able to translate the frequency and amplitude of a wave into a two-dimensional surface, where a gradient between black and white quantified amplitude, the darkest areas representing the highest amplitudes, and lightest areas the lowest ones. This is not the best tool for understanding what birds themselves hear or how they use their sounds. Sound spectrographs take human hearing as standard, and they use a linear Fourier analysis that cannot reflect the instantaneous change of frequencies in a series of tones. Therefore, micro-patterns that are important for identifying members of a group or individuals are often considered as noise. ${ }^{40}$ The machine initially depended upon other technologies, such as recording machines that would allow translation from the tape recording to the sound spectrograph under specific conditions. ${ }^{41}$ Similarly, the technology also relied upon a cultural framework that, as we shall see, nurtured a particular epistemic and participatory ecology.

Developed within the Bell Telephone Laboratories (BTL), the spectrograph was embedded within an economic framework that restricted its interests to distinguishing "relevant" and "redundant" information for human physiological standards. ${ }^{42}$ When the United States entered the Second World War, the BTL team was asked to continue their work on the sound spectrograph. ${ }^{43}$ During this time, it was developed as the vocoder technological counterpart, that is, as a decoder. This engagement directed the design of the apparatus towards two specific ends: oral message decryption and data compression (minimum data to keep the message's content understandable). The focus of the sound spectrographs on formant structure-the

39 See Per Alström and Richard Ranft, "The use of sounds in avian systematics and the importance of bird sound archives," Bulletin BOC 123 (2003): 114-135. For a typical case of the use of seen and unseen birds' spectrographic records for diagnosing a new species, see Bret M. Whitney and José Álvarez Alonso, "A new Herpsilochmus antwren (Aves: Thamnophilidae) from northern Amazonian Peru and adjacent Ecuador: The role of edaphic heterogeneity of terra firme forest, " The Auk 115, no. 3 (1998): 559-576. See alsoDonald J. Borror, "Intraspecific Variation in Passerine Bird Song," The Wilson Bulletin 73, no. 1 (1961): 57-78.

${ }^{40}$ Per Szöke and Miroslav Filip, "The Study of Intonation Structure of Bird Vocalizations: an Inadequate Application of Sound Spectrography," Opuscula zoologica (Budapest)14, no. 1-2 (1977): 127-154, on 128.

${ }^{41}$ The sound was recorded at a speed of $25 \mathrm{rpm}$, with a pre-amplification of $6 \mathrm{~dB}$ in the case of the human voice. It was then played back at $78 \mathrm{rpm}$, which amplified the frequency and reduced the playback time. Simultaneously, the signal was analyzed, subjecting it to an analyzed filter, producing a graphical record called spectrogram.

${ }^{42}$ Mara Mills, "Deaf Jam. From Inscription to Reproduction to Information," Social Text 28, no. 1 (2010): 35-58.

43 Ralph K. Potter, "Introduction to Technical Discussions of Sound Portrayal," The Journal of the Acoustical Society of America 18, no. 1 (1946): 1-3, on 2. 
distribution of energy around a particular frequency - was appropriate for this end. Both the success of the sound spectrograph in decrypting messages during the war and the notion of the intrinsically combinatory nature of bioacoustics lead to a boom of expressions about "decrypting" animal language and "decoding" the sound of birds fighting for "broadcasting time to broadcast their song." ${ }^{44}$

Before the spectrograph, a series of technologies had also been used in bioacoustics, including Edison wax cylinders, optical movie soundtracks, and discs. However, animal songs only began to be recorded systematically from the 1950s onwards. ${ }^{45}$ The first natural sound archives also appeared, beginning with the Borror Lab of Bioacoustics (1945, Ohio State University, US), then followed by the Tierstimmenarchiv (1952, Humboldt University, Germany) and the Macaulay Library of Natural Sounds (1956, Cornell University, US). Nevertheless, the sum of birdsong recorded by the end of the century remained somewhat meagre. Although it was estimated that the sound of 90 per cent of the world's 10,000 bird species had been recorded, many of them were poorly represented, making the comparative task expected from bioacoustics impossible. ${ }^{46}$ There are significant gaps in the recordings, so we know very little about the vocalisation of between 27,000 and 28,000 bird taxa. ${ }^{47}$

Furthermore, the procedure for processing sound recordings of birdsong and call comparison was standardised only in $1998 .{ }^{48}$ Morton Isler, Phyllis Isler and Bret Whitney detailed the methodology for comparing syntopic pairs of birds (birds who live in close enough proximity to be able to hear each other) that had similar vocalisations, and from whom at least ten recordings were available. ${ }^{49}$ After defining the set of subjects, recordings were screened and ranges, means, and standard deviations for each individual and for each species were calculated. To study the differences between vocalisations, a set of characteristics were defined. ${ }^{50}$ This fortified the aim of increasing the catalogue of birdsong recordings, a goal spurred by the anxiety to protect a biodiversity that was felt to be seriously endangered.

\footnotetext{
${ }^{44}$ See, for example, Brumm and Zollinger, "Avian Vocal Production," 199, 203; Slabberkoorn, "Singing in the wild," $193 \mathrm{ff}$.

45 Richard Ranft, "Natural sound archives: Past, present and future," Anais da Academia Brasileira de Ciências 76, no. 2 (2004): 455-465, on 456.

46 Ranft, "Natural sound archives," 457.

${ }^{47}$ Alström and Ranft, "The use of sounds," 128.

48 Ibid.

${ }^{49}$ Morton L. Isler, Phyllis R. Isler, and Bret M. Whitney, "Use of vocalizations to establish species limits in antbirds (Passeriformes: Thamnophilidae)," The Auk 115, no. 3 (1998): 577-590.

50 These are number of notes, each note being "an unbroken trace in the spectrogram" (Ibid., 580); duration, measured in seconds to the hundredth; pace; change in pace; frequency; change in frequency; amplitude; change in amplitude; note structure and tonality; change in note structure and tonality; and syntax.
} 
By this time, noise becomes a matter of historical and philosophical concern, as well as a threatening agent in bioacoustics literature. ${ }^{51}$ This growing interest in noise was expressed in bioacoustics in two ways: studies on the modification of birdsong in relation to noise, and attempts to eliminate background noise automatically from recordings made in natural environments. Although the former recognised noise as a permanent element in the evolution of bird physiology and behaviour (i.e. as part of their adaptative process), concerns about the automatic management of big data combined with notions of diversity preservation made noise seem an anomalous element in need of control. Moreover, environments in recovery, such as the area devastated by radiation known as the Chernobyl Exclusion Zone (CEZ), offered new models of noise-free environments (and undoubtedly comprised environments free from anthropogenic noise). Research of these areas depended, by definition, on continuous recording instruments that contributed to the increase of the new "data landscape." In both cases, noise became a neatly differentiated agent.

In technical terms, this involved the recording and representation of noise as something detachable and independent from the individualised song of a bird. This allowed an interpretation of the link between noise and song as mere superposition, rather than interaction. Likewise, noise's "ontological continuity" was produced - that is, its consideration as a continuous and constant existence. Procedures for measuring and recording noise tend to give spatial continuity to noise-constant occurrence in one place-and more continuity over time. ${ }^{52}$ Thus, for example, Brumm recorded the noise in two successive years (between April 28 and May 1, 2001, and between May 1 and May 12, 2002) in the same area immediately after recording the song of the birds ${ }^{53}$ However, measurements of noise in a specific area where birds' songs were recorded several months earlier can be made with a difference of two years. They are

\footnotetext{
51 See, for example, Stuart Sim, Manifesto for Silence: Confronting the Politics and Culture of Noise (Edinburgh: Edinburgh University Press, 2007); also the historical studies about the different meanings of silence and noise before, during, and after the Second World War: Peter A. Coates, "The Strange Stillness of the Past: Toward an Environmental History of Sound and Noise," Environmental History 10, no. 4 (2005): 636-665; Karin Bijsterveld, "The Diabolical Symphony of the Mechanical Age: Technology and Symbolism of Sound in European and North American Noise Abatement Campaigns, 1900-40," Social Studies of Science 31, no. 1 (2001): 37-70; Carolyin Birdsall, Nazi Soundscapes. Sound, Technology and Urban Space in Germany, 1933-1945 (Amsterdam: Amsterdam University Press, 2012); Annelies Jacobs, "The Silence of Amsterdam Before and During World War II," in Sounds of Modern History: Auditory Cultures in 19th-and 20th-Century Europe, ed. Daniel Morat, 305-322 (Oxford/New York: Berghahn Books, 2014). The first report on bird change of pitch in urban environments was Hans Slabbekoorn and Margriet Peet, "Ecology: Birds sing at a higher pitch in urban noise," Nature 424, no. 6946 (2003): 267.

52 Dowling, Luther, and Marra, "Comparative effects," 2; Henrik Brumm, "The impact of environmental noise on song amplitude in a territorial bird," Journal of Animal Ecology 73 (2004): 434-440, on 436.

${ }^{53}$ Brumm, "The impact of environmental noise," 435-36.
} 
also performed in months in which anthropogenic noise is higher. ${ }^{54}$ This ensures a greater continuity of noise, and makes visible the potential overlap that would occur if birds did not have adaptive strategies. Noise became a steady, predictable, robust presence from which specifications can be derived to establish thresholds for cohabitation. At the same time, this process naturalised birdsong as a stable production inscribable in different backgrounds and different environments. This series of techniques would then be introduced and consolidated into the automatic recognition and classification of birdsong.

\section{Automatic Recognition and the De-noised Extended Specimen}

With automatic recording and the reproduction of birdsong, ornithology entered schizophonia, the phenomenon of the dissociation between the heard sound and its source. ${ }^{55}$ Moreover, efforts to fill gaps in our knowledge and in our archives concerning birdsong led to a paradoxical situation: scientists had at their disposal an increasing amount of data that could hardly be analysed and processed fast enough by the available human experts. Artificial intelligence software able to recognise the presence of specific types of birds and to classify their songs was developed to tackle bioacoustics big data. This was especially useful in cases where the environment was impenetrable, both literally, as was the case for researchers working on the Chernobyl Exclusion Zone, and metaphorically, as in loud noise or dense informational environments.

In this way, birds entered the world of the automation of "the extended specimen," that is, "a constellation of specimen preparations and data types that, together, capture the broader multidimensional phenotype of an individual, as well as the underlying genotype and biological community context from which they were sampled." ${ }^{56}$ Such considerations are implicit in Alström and Ranft's specifications for the increasingly systematic collections of standardised bird sound recordings. ${ }^{57}$ However, automatic recognition changed the way that such recommendations about data production and assembling worked. The "information environment" that it produced favoured a particular selection of traits that were centred

\footnotetext{
54 Bermúdez-Cuamatzin et al., "Strategies of Song Adaptation," recorded male house finches in 26 locations from May 17 to July 7 in 2006. Noise levels were measured at the same locations between September 1 and October 25 in 2006; and again, in October 2008, in a sub-sample of the 26 sites. The authors measured noise in September to avoid the "Mexican holiday period during which noise levels are typically reduced." The different recordings of the bird are coupled with the levels of noise measured in the area, and then ranked accordingly.

55 Murray R. Schafer, The New Soundscape. A Handbook for the Modern Music Teacher (Ontario: Berandol Music Limited, 1969), $43 \mathrm{ff}$.

56 Michael S. Webster, "The Extended Specimen," in The Extended Specimen: Emerging Frontiers in Collections-based Ornithological Research, ed. Michael S. Webster, 1-9 (Boca Raton: Taylor \& Francis, 2017), 1.

57 Alström and Ranft, "The use of sounds," 126-127.
} 
around human hearing, along with ways of stabilising relations between layers of sound (with clear distinction between foreground and background and stable thresholds), and a lineal style of interference and endangerment prediction.

Until 2006, birds had been automatically monitored in designated places like airports, where they could cause great damage. However, neither radars nor cameras could distinguish between types of birds. Following the common assumption that human speech and birdsong share frequency ranges, the proposal of Kwan et al. was to produce a standardised, species-agnostic process for automatic sound recognition in "noisy and multispeaker environments," with multipurpose strategic uses as:

...wildlife monitoring, endangered species monitoring in inaccessible areas, speech enhancement in communication centers, conference rooms, aircraft cockpits, cars, buses, and so forth. It can be used for security monitoring in airport terminals, and bus and train stations. The system can pick up multiple conversations from different people and at different angles. It can also be used as a front-end processor to automatic speech recognition systems. ${ }^{58}$

Five years later, automatic recognition was still fighting noise. ${ }^{59}$ By 2016, many of the automatic birdsong recognition systems were still not entirely automatic, requiring human processing. However, the promises and meaning of visualising the precise thresholds of each singing species were becoming more widespread through historical interpretations of primeval soundscapes. Bernie Krause argues that the "orchestral harmony" of non-anthropogenic natural sound occurs as each species occupies a distinct bandwidth: ${ }^{60}$ spectrograms are simply able to make visible the ways that environmental sounds determine the sonic niche of each of them. As Whitehouse noted, it is against this properly arranged, primaeval soundscape that industrial and anthropogenic sound is compared and appears disruptive and meaningless noise. ${ }^{61}$

The interpretation of sound niches, depurated from adjacent noise or, at least, neatly differentiated from their environment, is also accompanied by a sense of unveiling and veracity also associated with audio surveillance. Niches make the fundamental aims of machine learning and artificial intelligence credible: sustained and stable discrimination between elements, the

${ }^{58}$ C. Kwan,1 K. C. Ho, G. Mei,1 Y. Li, Z. Ren,1 R. Xu,1 Y. Zhang,1 D. Lao,1 M. Stevenson,1 V. Stanford, and C. Rochet, "An Automated Acoustic System to Monitor and Classify Birds," EURASIP Journal on Applied Signal Processing 2006, 96706 (2006): 1-19, on 1.

59 See Peter Janč ovič and Münevver Köküer, "Automatic Detection and Recognition of Tonal Bird Sounds in Noisy Environments," EURASIP Journal on Advances in Signal Processing 2011, 982936 (2011); Ilyas Potamitis, Stavros Ntalampiras, Olaf Jahn, and Klaus Riede, "Automatic bird sound detection in long real-field recordings: Applications and tools," Applied Acoustics 80 (2014): 1-9.

${ }^{60}$ Bernie Krause, The Great Animal Orchestra. Finding the Origins of Music in the World's Wild Places (London \& New York: Little, Brown and Company, 2012).

${ }^{61}$ Andrew Whitehouse, "Listening to Birds in the Anthropocene: The Anxious Semiotics of Sound in a Human-Dominated World," Environmental Humanities 6 (2015): 53-71. 
identification of parts, and recompositing under an enunciable rule. This approach also presupposes that a mechanical approach is superior to sound recognition because it avoids the "bias to observer variations" caused by idiosyncratic appreciation. ${ }^{62}$ Under the influence of this prejudice, the practitioner forgets that the terabytes of information recorded by remote acoustic monitoring projects are, in fact, all produced in connection with the tactics, instruments, needs, anxieties, cultural expectations and spectral references of human beings. Therefore, under the aegis of artificial intelligence cohabitation is understood generally under the metaphor of a pigeonhole, that is, as coexistence without interaction or interference.

Interestingly, however, a generalised recorded environment can give the extended bird specimen some ghostly characteristics. The pressure to generate recordings in cases where extinction is a possibility can make time go out of phase, especially when recognition is difficult or is deferred indefinitely. How do we know if the recording is of an existing bird or of an extinct one? If a similar recording is never produced again, has the bird disappeared or has it changed its singing?

Additionally, birds became viewed as indicators of environmental health and the basic observation regarding the extended specimen had to be defined according to possibilities of political intervention. The question was no longer how do birds relate and react to their environments, but how can we use the information provided by birds to manage those environments correctly? "Do we need to know about each vocalisation separately? Do we need to know how many vocalisations, or how many individuals, or just an overall presence/ absence?" ${ }^{63}$ Different levels of information required different computational approaches. To attain the goal of processing unattended field recordings by automatic birdsong recognisers would require an even broader definition of noise:

... calls from birds that are a long way from the recorder can be faint or corrupted, and there are overlapping calls from many different birds. ${ }^{64}$

Automatic bird recognisers are connoisseurs of their areas, trained to identify only the songs of local birds. In many senses these machines are quite human: they have trouble in distinguishing the target when competing species are vocalising in the same bandwidth. However, they are also quite bird-like: they miss distant sounds that can be heard by humans. To avoid misses and false positives, attempts have been made to train these programmes to detach a target set of signals from a background set of signals. But since often it is hard to provide pre-

\footnotetext{
${ }^{62}$ Nirosha Priyadarshani, Stephen Marsland, and Isabel Castro, "Automated birdsong recognition in complex acoustic environments: a review," Journal of Avian Biology 49, no. 5 (2018): 1-27, on 1.

${ }^{63}$ Dan Stowell, Mike Wood, Yannis Stylianou, and Hervé Glotin, "Bird detection in audio: A survey and a challenge" (paper presented at the IEEE 26th International Workshop on Machine Learning for Signal Processing (MLSP) Vietri sul Mare, 2016), 1-6, on 2.

${ }^{64}$ Priyadarshani, Marsland, and Castro, "Automated birdsong recognition," 1.
} 
processed samples of the target bird species, sometimes the resulting pattern of this training is rather weak. The use of automatic soundscape screening in the search for matching birdsong templates is an entirely new way of hearing that produces new kinds of aural ontologies.

At this point, however, the ontologies that have guaranteed an accurate taxonomy have revealed their deeply historical condition. Changes in bird-singing are at the same time considered part of a natural mechanism and an imposed burden caused by anthropogenic noise. What happens, however, if the same species modifies its song enough as to create an interspecies difference? What happens when birdsongs no longer match the standardised thresholds that shape our knowledge about them? Is the system making the presence of birds more robust or, on the contrary, is it weakening their presence and ability to shape their environment? What has the environment become beyond a bunch of oddly articulated data? What does cohabitation mean in this environment?

Lost in the intersection between three types of environments (noise, second nature, and data environments), birds stop fitting expectations. They become residual: the unreachable, ambiguous, uncontrollable, complex, fluctuant remains of a desiccated reality. ${ }^{65}$ Birds also emerge as an unfolding reality that exists beyond direct human experience, that can escape monolithic narratives based on specifications as tools for stabilising de-contextualisation. What are the recordings of bird's songs evidence of? To ask this question requires us to compare how we deal with other cases of vulnerability where stabilisation is equally difficult to understand.

\section{A Proper Place to Breathe: Iron lungs and the Orthopaedics of Breathing}

Iron lungs or tank respirators entered the market before their developers had a specific user in mind for their product. Therefore, some have considered it either a premature or halfway technology. ${ }^{66}$ The uncertain contours regarding its functions, shape, and place in the context of established values and medical practices marked its path in contemporary history. Following its development will give us the chance to consider the many stages and adaptations to the environment undergone by technologies. Each failed attempt to solve concrete objections or to define improvements progressively shaped the machine, as each set of participants or users became linked to it. Such a process is one of production of specifications that lead to a non-linear series of standardisations related to adjustments and nestlings into previous infrastructures and

65 Susan Leigh Star and Geoffrey C. Bowker, "Enacting Silence: Residual categories as a challenge for ethics, information systems, and communication," Ethics and Information Technology 9 (2007): 273280, on 274.

${ }^{66}$ James H. Maxwell, "Halfway Technology or Necessary Step?” The Milbank Quarterly 64, no. 1 (1986): $3-29$. 
organisations. Underlying this flows an essential discussion on what was being preserved and where the limits of precariousness and vulnerability were.

Roughly speaking, the history of tank respirators can be divided into three stages. The first, from 1920 to 1938, can be considered as the phase of functional definition, in which notions of vulnerability began to instil into the mechanical and human bodies involved. This was the period of assessment of initial benefits, commercialisation, and patent wars. There were 150 Drinker respirators in the US in 1931, and the mortality rate of those who used them was amazingly high at 78 per cent. The case of Frederick B. Snite Jr. (1910-1954), the rich and popular infantile paralysis victim from Chicago that in 1936 started to live in an iron lung, opened up the perception of the respirator as both a life-saving technology and an iron cage. From 1929 to 1933, Warren-Collins Inc. produced 222 Drinker respirators, but in the following four years, the company built only 28 more. For his part, John Haven Emerson (1906 - 1997) produced barely 50 units of his model after 1931. However, after Drinker's patents were withdrawn in 1935, the positive publicity from cases such as Snite's gained a better reputation for the machine, and the market increased hugely.

Thus, the second stage runs from 1939 to 1952 . Tank respirators were commodified, mainly in the US, where the National Foundation for Infantile Paralysis (NFIP) began to mass distribute thousands of these apparatuses to assist in both the hospital and home-care treatment of acute poliomyelitis patients. The attempts of individual philanthropic efforts to make a technology costing between 2,000 and 3,000 dollars available at many different places was progressively replaced by a policy of bringing patients and collective professional assistance together in the ward. In 1950, the first of thirteen Respiratory Centres in academic hospitals was opened by the NFIP. The increase of iron lung units followed the outbreaks of poliomyelitis in the US, the partner illness that co-evolved along the design of respirators. Following the outbreak of $1949,40,000$ cases were reported in the US. ${ }^{67}$ In 1952, the number rocketed to 58,000. Although the chances of being permanently disabled or dying were very small, ${ }^{68}$ a sense of urgency spurred on the development and approval of standardised procedures for intensive care in this year. This was encouraged predominately by the elaborate care required by patients in the tank respirator.

The final stage of the iron lung's evolution came in the period after the development of the polio vaccine. Artificial respiration and iron lungs were normalised to the extent that respiratory centres were considered essential parts of large general hospitals. The structure of care that had been developed to treat polio patients became the model or the departure landscape for any other respiratory patient (The Lancet 32, February 1957).

${ }^{67}$ David M. Oshinsky, Polio: an American Story (Oxford University Press, 2005), 4, 81.

${ }^{68}$ Ibid., 81. 
These stages did not flow smoothly from one to another. There was no progressive and steady perfecting of the machine towards a definite end. Such a narrative is incomplete and conceals the immense effort and the bewildered assumptions behind the new artefact. The following paragraphs aim to explain the transitions tank respirators underwent to define suitable agentsmachines, patients, carers—and effective specifications for a successful functional purpose.

\section{Liminality: Nestling the Function}

Between the First and the Second World Wars, the model for mechanical respiration was dominated by negative pressure ventilation. ${ }^{69}$ The justification for the existence of the "iron lung" was marked by patients with respiratory dysfunction in general, and decisively by the poliomyelitis epidemics of the thirties, forties, and fifties. Before the 20th century, there were models and prototypes designed to assist patients with respiratory deficiency. Some of these were remarkably like the machines that would eventually become popular in the USA in the 1930s. However, the apparatus that would definitively consolidate medical care and demonstrate its viability as a clinical instrument came from Sweden.

Torsten Thunberg (1873 - 1952) was a renowned professor of physiology and biochemistry at the Physiological Institute at the University of Lund. Designed in the 1920s, his Barospirator was a straightforward application of Boyle-Mariotte's law in a nestled structure. This law states that a flask within a bigger container will be subject to changes of air pressure that occur within the larger container, and in such a way that ventilation will take place without any change of volume. Based on this principle, he designed the apparatus (see Figure 1). Respiration was a result of "rhythmic pressure differences between outside air and pulmonary air." ${ }^{\text {" Hence, }}$ Thunberg stated: "Our lungs can now be regarded as gas containers that communicate freely with the atmosphere in open glottis and under normal conditions. They therefore show the same gas pressure as that prevailing in the atmosphere." ${ }^{71}$ Under these conditions, where the iron booth or chamber takes the place of normal atmosphere, what Thunberg called normal "volumetric breathing" could be substituted by "pressurised respiration." The whole apparatus weighed 1,600 kilograms, and the chamber where the subject lay comprised an enclosed iron tube two meters long and $60 \mathrm{~cm}$ in diameter. The subject was introduced feet-first into the chamber through a door that sealed hermetically over his head. At face level there was a small round window with mirrored glass to allow observation of the subject. The Barospirator was thus both terrifying and compelling technology.

${ }^{69}$ C. H. M. Woollam, "The development of apparatus for intermittent negative pressure respiration," Anaesthesia 31 (1976): 666-685.

70 Torsten Thunberg, "Der Barospirator, ein neuer Apparat für künstliche Atmung," Skandinavisches Archiv Für Physiologie 48, no. 2 (1926): 80-94, on 80.

${ }^{71}$ Except otherwise noted translations are mine. 


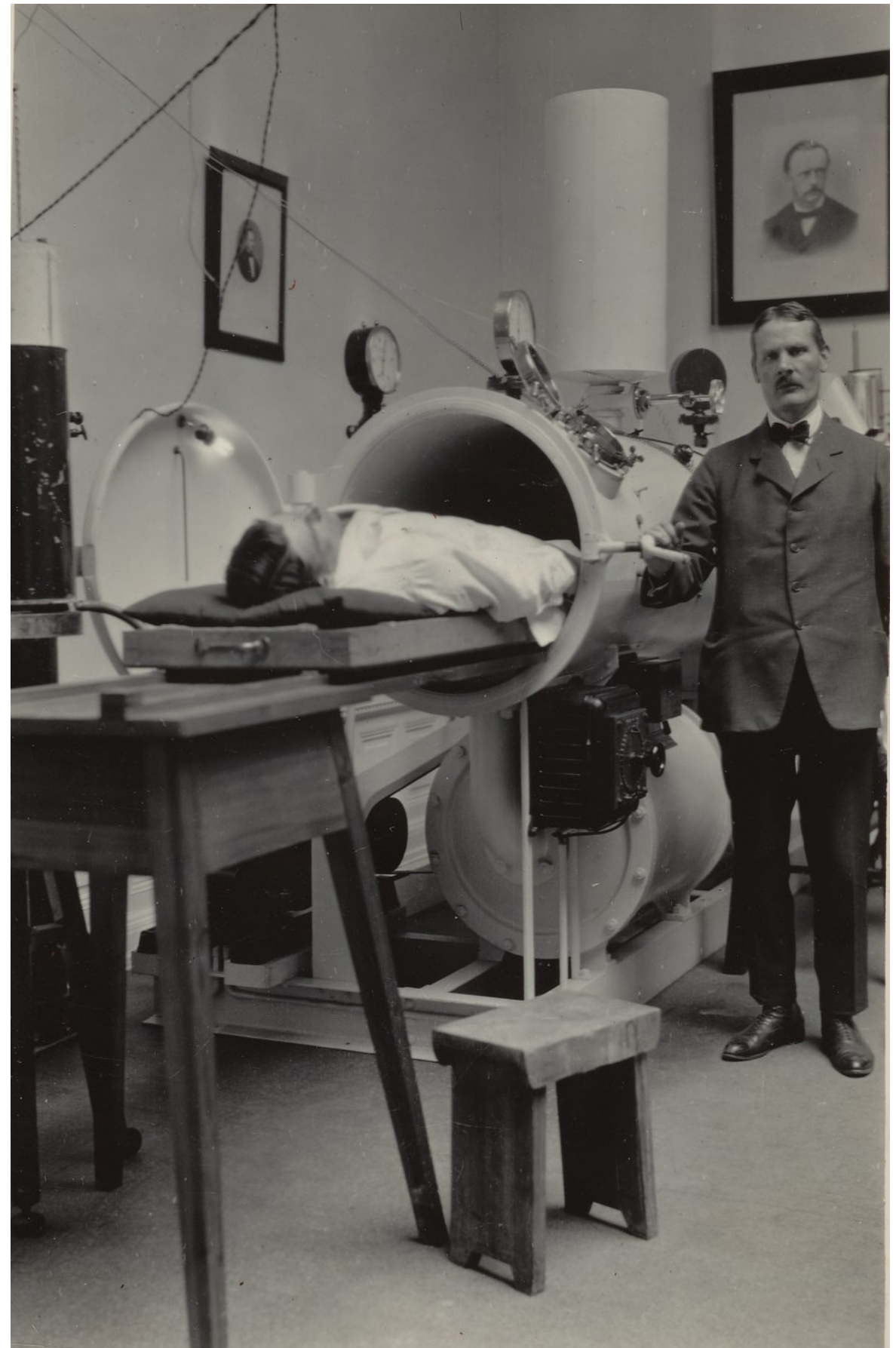

Figure 1 - Thunberg with the barospirator in his laboratory.

Benedict, "Reports of Visits to Foreign Laboratories," Francis A. Countway Library of Medicine.

Center for the History of Medicine, Harvard University. Public domain. 
To work appropriately, that is, to assure the proper ventilation of the lungs, the machine required the patient to stop breathing, either voluntarily — with open glottis—or spontaneously. Thunberg claimed that "the subjects were able to spend hours in the Barospirator without breathing, and their fresh pink skin colour was evidence that this method of artificial respiration has solved its task in the most satisfying way." ${ }^{72}$ However, Henrik Erghoff's 150-page report, published in 1927, suggested that holding one's breath was far more difficult than his superior and supervisor realised. Spontaneous apnoea rarely occurred, and most people can hardly hold their breath under specific pressure and frequency conditions. ${ }^{73}$ When active apnoea, that is, voluntary respiratory arrest, is not possible, the subject must adapt her breathing to the compression and de-compression rhythms.

The apparatus bestowed an entirely new status onto the patient. It was not a prosthetic device; it was a new way of facilitating organic reparation from a functionally equivalent point of view. As the American doctor Francis Gano Benedict (1870-1957) observed with total enthusiasm and insight, they were dealing with "metabolism lower than basal, that is, the ordinary basal metabolism less the work of respiration," which opened "a new chapter in respiratory physiology." ${ }^{4}$ The patient thus entered a state of liminality between life and death, in which, paradoxically, the possibilities for recovering her health increased. Such a space had never existed before.

Interestingly, it was assumed that this machine provided autonomy to the patient, since her symbiosis with the machine did not depend upon the presence of an expert the same way that the pulmotor did. In 1924, when Thunberg began his research on the Barospirator, Cecil Kent Drinker (1887-1956), a North American expert in respiratory failure and resuscitation (and whose brother, Philip, would later produce the Drinker Respirator) wrote about the disappointing state of artificial respiration. Cecil Drinker found that "devices now available for driving air or oxygen into the lungs by positive pressure were inadequate and unphysiologic."75 Four years later, when he came to know about the Barospirator, he found it fascinating. ${ }^{76}$ The core idea was to produce a stable microenvironment in which a patient with impaired wall-

\footnotetext{
72 Thunberg, "Der Barospirator," 86.

${ }^{73}$ Henrik Enghoff, "Der Barospirator 1: Untersuchungen über seine Wirkungsweise mit besonderer Berücksichtigung der pneumographischen Methodik," Skandinavisches Archiv Für Physiologie 52, no. 3 (1927): 1-168, on 138.

${ }^{74}$ Francis Gano Benedict, Reports of Visits to Foreign Laboratories, seven volumes, 1907-1933, volume 5, on p. 52, Series: II. Boston Nutrition Laboratory Records, 1904-1954, Francis A. Countway Library of Medicine.

75 Cecil Kent Drinker, "Artificial Respiration in Electric Shock and Gas Poisoning," Journal of the American Medical Association 83, no. 10 (1924): 764-765, on 765.

76 Cecil Kent Drinker, "New Apparatus for Artificial Respiration: the Barospirator of Professor T. Thunberg," Journal of Industrial Hygiene 10 (1928): 7-12.
} 
chest muscular tone could "reside" for a long period of time. ${ }^{77}$ In the case of the Barospirator, its liminality initially entailed a break with atmospheric and social surroundings. Soon after, however, a chamber for the scientific team directly connected to the inner stretcher by an open window was added so that they might observe and interact with the patient. This created a shared artificial space; it was a niche that admitted temporary visitors.

Philip Drinker, however, was mainly interested in recovering paralysed intercostal muscles, and so the movement of the patient's chest had to be maintained during treatment in the respirator. Consequently, the patient was in contact with the atmospheric environment. Therefore, instead of being entirely enclosed in the chamber, the head would protrude from the lid that enclosed the body. The hole the head went through was surrounded by a rubber collar that prevented the passage of air. In this case, apnoea or the suspension of volumetric breathing was not necessary; negative pressure took place to help move the pulmonary wall. The patient was not only between life and death, or survival autonomous state and a survival dependent state; he was also in between an atmospheric and a non-atmospheric space, between a socialising and a non-socialising space. The head would be the part of the patients' bodies that would be visible and could directly interact with other people. Based on Dr. Eugène Joseph Woillez's Spirophore (1876), the Drinker machine would develop in the opposite direction to the Barospirator. Conceived much more as a cell than a cocoon, huge respirators soon appeared with several "cells" for the treatment of children. Cells and hives would prove useful for saving space and for providing quick attention to children during the 1950s epidemics in the US. Drinker saw Thunberg's respirator as an alternative to his own in 1928, but two years later he stressed that his model allowed the patients to eat, drink and sleep while in the respirator "without having the pump stopped." Accessibility, comfortable handling of the patient, and her/his own comfort became a priority. This necessitated increasing definition of what an intensive care patient was and the standardised stages that (s)he had to accomplish to transition into a state of self-care and, if possible, autonomy.

In the 1940s, following Barach's modifications of Thunberg's Barospirator, Emerson's and Drinker's model, respectively, began to include a dome to allow transition to positive pressure ventilation when the patient was removed from the respirator to be nursed, fed, and cleaned. For the first time, the patient was spared the feeling of his/her own condition entirely, even if only for a few seconds. Their "normal" or normalised state became intertwined with the tank respirator. Moreover, since changes in design stressed comfort and safeness to the patient, the ability to live for prolonged periods of time within the iron lung was an indication of technological success. However, this kind of onto-technological stability between the machine

\footnotetext{
77 The term is used precisely in the title of Alvan L. Barach's important paper "Continuous Immobilization of the Lungs by Residence in the Equalizing Pressure Chamber in the Treatment of Pulmonary Tuberculosis," Diseases of the Chest 12, no. 6 (1946): 521-537.
} 
and the patient posed unsettling questions to doctors: Were the lives of those that became dependent on the machine worth living? What is "saving a life"?78 What was most disturbing was that many patients became used to their tanks and felt so at ease living within them that doctors began to consider the apparatus a hindrance for cure, understood as the possibility to make patients regain autonomy from the apparatus.

In defining the function of the machine and the most suitable patients to benefit from it, tank respirators produced unfamiliar or uncanny ontologies. The choice between models and designs was less straightforward than might appear. There were discrepancies concerning how the specifications should be designed to produce, or preserve, a desired social model and its values. One of the issues that had to be resolved soon to tip the balance towards one solution or another would be time and timing.

\section{Timing Times: Nestling the Habitat}

Initially, according to Thunberg, the Barospirator was intended to assist in at least three types of cases: asphyxial newborns; cases of breathing inhibition due to gas poisoning, drugoverdose, or electrical shock that would require urgent and sometimes prolonged help of breathing restoration; and respiratory paralysis caused by poliomyelitis. Sweden, as other European countries, had suffered from severe epidemics of polio between 1911 and 1913, with 10,000 polio victims. ${ }^{79}$ These different groups of patients needed different timing and duration of Barospirator use. Asphyxial newborns were supposed to require only a short time in the machine before recovering normal breathing; though in this case modifications in the machine's design to aspiring the child's mucus in the pharynx and trachea would be required. Intoxicated and poisoned people - a primary concern for Cecil K. Drinker as an industrial physicianwere also expected to spend a relatively short term in the apparatus. On the contrary, patients suffering from respiratory paralysis, as in cases of acute poliomyelitis, were expected to spend much longer within the machine. It is around these permanent conditions that discussions concerning the microenvironmental needs of patients with respiratory impairment and, therefore, on respirators were to take shape. As Karl Petrén (1868-1927) put it, poliomyelitis patients would become the "classic example for testing the mode of action of the apparatus." ${ }^{80}$

\footnotetext{
78 The question arose in cases of "patients who have survived after long and expensive dependence on a respirator but who are so extensively paralyzed that one can wonder as to the value of their lives to themselves or to others." James L. Wilson, "The Use of the Respirator," Journal of the American Medical Association 117, no. 4 (1941): 278-279, on 278.

79 Per Axelsson, “'Do not eat those apples; they've been on the ground!': Polio epidemics and preventive measures, Sweden 1880S-1940S.” Asclepio 61, no. 1 (2009): 23-38.

${ }^{80}$ Karl Pétren and Einar Sjövall, "Eine Studio über die tödliche akute Form der Poliomyelitis," Acta Medica Scandinavica 64, no. 1 (1926): 260-291, on 269.
} 
As Paul Wilhelm Fritsch noted, few cases concerning the use of the Barospirator in Lund and Stockholm were published before his own 1932 paper. There was little similarity between the protocols of use in each case. In Petrén's first case, for example, the patient stood for 51 hours in the Barospirator, with short breaks of about five minutes approximately every three or four hours. ${ }^{81}$ The case reported by Henry Marcus was quite different. The patient underwent treatment at the Serafimer Lasarettet almost seven months. She was prescribed Neosalvarsan on entering the hospital. After five months of slow improvement, the patient's condition deteriorated in mid-March. On the 4th April, she was removed to the Barospirator, and was placed under the supervision of Fritsch, who oversaw the apparatus. She spent 24 hours inside it before dying of pneumonia. ${ }^{82}$ This granted her enough time for a proper farewell with her relatives.

During 1928 and 1929, Fritsch was concerned about the dependence of patients on the Barospirator, specifically about "the chance of [their] living outside the apparatus." ${ }^{33}$ Therefore, the time they spent inside the apparatus was tightly controlled, and treatment was suspended as soon as asphyxia symptoms subsided and their vital signs stabilised. This practice involved varying lengths of treatment intervals or suspension periods, which in some cases exceeded the total duration of patients' time inside the respirator.

For their part, US researchers produced a steady series of publications about the machine and highlighted the number of continuous hours within the respirator as an argument in favour of its usefulness and viability. Patients spent hundreds of hours in the respirator. The first case of a patient with acute poliomyelitis with anterior paralysis who recovered thanks to the respirator took place in 1929, and required 664 hours of treatment in the tank. ${ }^{84}$ The second successful case, also in 1929, took far fewer hours of treatment at 140. In this case there was no urgent need for the respirator. The patient, a 10 -year-old child, began to ask to be put into it since it was a comfort zone that improved sleep and lessened anxiety. ${ }^{85}$ The sense of relief and security became a major reason to use the tank. The third case of successful treatment of this disease, a 25-year-old adult, was to come in the late 1930s and involved a respirator stay

\footnotetext{
${ }^{81}$ Ibid., 269-272.

${ }^{82}$ Henry Marcus, "Encephalitis lethargica- Sclérose en plaques. Eine Differentialdiagnostische Studie (Aus der Nervenklinik des Karolinischen Institutes in Stockholm)," Acta Psychiatrica Scandinavica 5, no. 2 (1930): 129-150, on 138.

${ }^{83}$ Paul W. Fritsch, "Experiences in the Treatment by the Barospirator," Acta Medica Scandinavica 78, no. 2 (1932): 100-125, on 117.

${ }^{84}$ George H. Shambaugh, William G. Harrison and J. I. Farrell, "Treatment of the Respiratory Paralysis of Poliomyelitis in Respiratory Chamber. Report of Three Cases, with One Recovery," Journal of the American Medical Association 94, no. 18 (1930): 1371-1373.

85 Philip Drinker, Thomas J. Shaughnessy, and Douglas P. Murphy, "The Drinker Respirator. Analysis of Case Reports of Patients with Respiratory Failure Treated form October, 1928, to June, 1930," Journal of the American Medical Association 95 no. 17 (1930): 1249-1253, on 1250.
} 
of more than 2,000 hours. ${ }^{86}$ Despite this data, James L. Wilson still complained in 1940 about the lack of knowledge concerning the real benefits of the apparatus. ${ }^{87}$

During the first decade of use, failure to save poliomyelitis patients had cast doubt upon the usefulness of the machine. Until 1932, there was no a profile of the kind of polio patient that could benefit from the use of the machine, and so its efficiency could not be assessed adequately. This year, James L. Wilson published a review demonstrating that cases of respiratory deficiency with paralysis of the intercostal muscles and/or the diaphragm improved with time spent in the machine. ${ }^{88}$ These patients were able to synchronise their breathing with the machine, and even to fall asleep in it. They could remain inside for an extended period. However, children with bulbar poliomyelitis could not synchronise their respiratory effort with the machine due to an apparent reflex closure of the glottis in the inspiratory phase of the machine (Wilson reviewed 11 cases). In other words, the patient was unable to cooperate, which exonerated the machine of inefficiency. This synchronisation was typical of Drinker/Emerson iron lungs, and so they imposed this specification on their potential users. Wilson also explored at what stage of their disease patients should be referred to the apparatus, and what the lateral effects might be. Finally, he posed a crucial question: Was it worth investing so much in respirators and patients with intercostal and/or diaphragmatic paralysis, when bulbar paralysis patients doubled their number in a ratio of $1: 2$ of total of patients treated?

In the following decade, the figures, questions, and answers changed. The age of patients affected by poliomyelitis, and hence paralysis, had increased. By 1940, 29 per cent of the victims of poliomyelitis were under 10 years of age, 41 per cent between 10 and 20 years, and 30 per cent over $20 .{ }^{89}$ By the end of the 1950 s, a similar proportion could be found, for example, at the Respiratory and Rehabilitation Centre at the Creighton Memorial-St. Joseph's Hospital (Ohama, Nebraska), where 64 per cent of patients were between 10 and 30 years old. ${ }^{90}$ However, mortality had reduced from 50 per cent to 20 per cent. As the iron-lungs began to work more reliably, doctors seemed increasingly concerned about the new reality of "a quadriplegic patient who continued to require respiratory aid." ${ }^{11}$ It was estimated that in

\footnotetext{
${ }^{86}$ John Favill and Thomas L. Fentress, "A Case of Respiratory Paralysis in Poliomyelitis Successfully Treated in a Respirator," Journal of the American Medical Association 97, no. 20 (1931): 1464-1465.

${ }^{87}$ James L. Wilson, "The mechanical respirator in poliomyelitis," The Journal of Pediatrics 16, no. 4 (1940): 462-467.

${ }^{88}$ James L. Wilson, "Respiratory Failure in Poliomyelitis. Treatment with the Drinker respirator," American Journal of Diseases of Children 43, no. 6 (1932): 1433-1452.

${ }^{89}$ Editorial, "The value of respirators in poliomyelitis," Journal of the American Medical Association 117, no. 4 (1941): 292-293, on 292.

${ }^{90}$ Harold N. Neu, "Rehabilitation of the Patient with Long-Term Respiratory Paralysis," Journal of the American Medical Association 168, no. 12 (1958): 1610-1617, on 1611.

${ }^{91}$ Ibid., 1610.
} 
1954 at least 1500 people were residing in respirators of one kind or another ${ }^{92}$ and that at least 500 of them were to occupy an iron lung permanently. ${ }^{93}$ As the cost of caring for these patients rocketed, the time for weaning from the respirator became crucial. However, the concrete timespan after onset that would be idoneous for guaranteeing non-dependence of the machines remained unassessed.

In 1955 Wilson and Dickinson speculated that being respirator-free (which did not mean being free of all mechanical aids to respiration) depended on four factors. ${ }^{94}$ Two of them were physiological-irreversible damage of anterior horn cells that control the respiratory muscles, and loss of "pulmonary compliance" due to loss of elasticity of the thoracic cage. The other two were psychological, related to comfort and motivation. As said, many patients became comfortable in the iron lung. This meant that they had attained an equilibrium with the machine that now was considered harmful by doctors. In their view, patients had "learned to demand" greater pulmonary ventilation than needed and became increasingly comfortable with respiratory alkalosis (psychogenic hyperpnoea). Having attained this symbiotic stasis, patients lost the motivation to free themselves from the tank, hindering any belief in a future outside it.

Although doctors made a distinction between psychological and biochemical dependence on hyperpnoea, both required a weaning procedure. This implied a displacement of the patient's will and opinion, and a stricter protocol to control for assuring the transitoriness of residence in what was now considered a survival — and hence, temporary — environment. Part of the protocol was fostering competition amongst patients to leave the iron lung as soon as possible. Effort and endurance of some respiratory labours were applauded, as a way of prizing resistance to the enticing comfort that these spaces provided.

In their search for a method to remove the patient from the respirator, doctors deconstructed the bonds that produced stable environments. The liminal spaces so carefully constructed became spaces where there was nothing to be desired, and time proved to be a suitable mechanism for defining the state of liminality. Permanent liminality fostered notions of alternative, substitutive or equivalent environments. However, time spent within the tank was not the only factor considered when defining viable environments for the patient, whether stable or transitory. Space and modularity were also important components, since they provided the determinant conditions for infrastructural nestling, that is, for tuning the machine using

${ }^{92}$ John E. Affeldt, "Recent Advances in the Treatment of Poliomyelitis," Journal of the American Medical Association 156, no. 1 (1954): 12-15, on 12.

${ }^{93}$ James L. Wilson and David G. Dickinson, "Prevention of Long-Time Dependence of Poliomyelitis Patients on Tank Respirator," Journal of the American Medical Association 158, no. 7 (1955): 551-555, on 551.

${ }^{94}$ Wilson and Dickinson, "Prevention of Long-Time Dependence." 
already-established practices and technical networks.

\section{Modularity and Infrastructural Nestling}

From a technical point of view, individual encapsulation was not an unavoidable requirement for a well-performing respirator. In 1926, Carl Holmbergs Mekaniska Verkstads filed a patent application for the Barospirator that differed in his design from Thumberg's original apparatus. Whereas the original machine was, as described above, an enclosed tube, the new Barospirator (at Karl Petrén's clinic in Lund), had a small observation cabinet connected to the tube where the patient lay (see Figures 2 to 4). This allowed not only more control over the patient's body but also a shared experience by doctors of pressurised respiration.

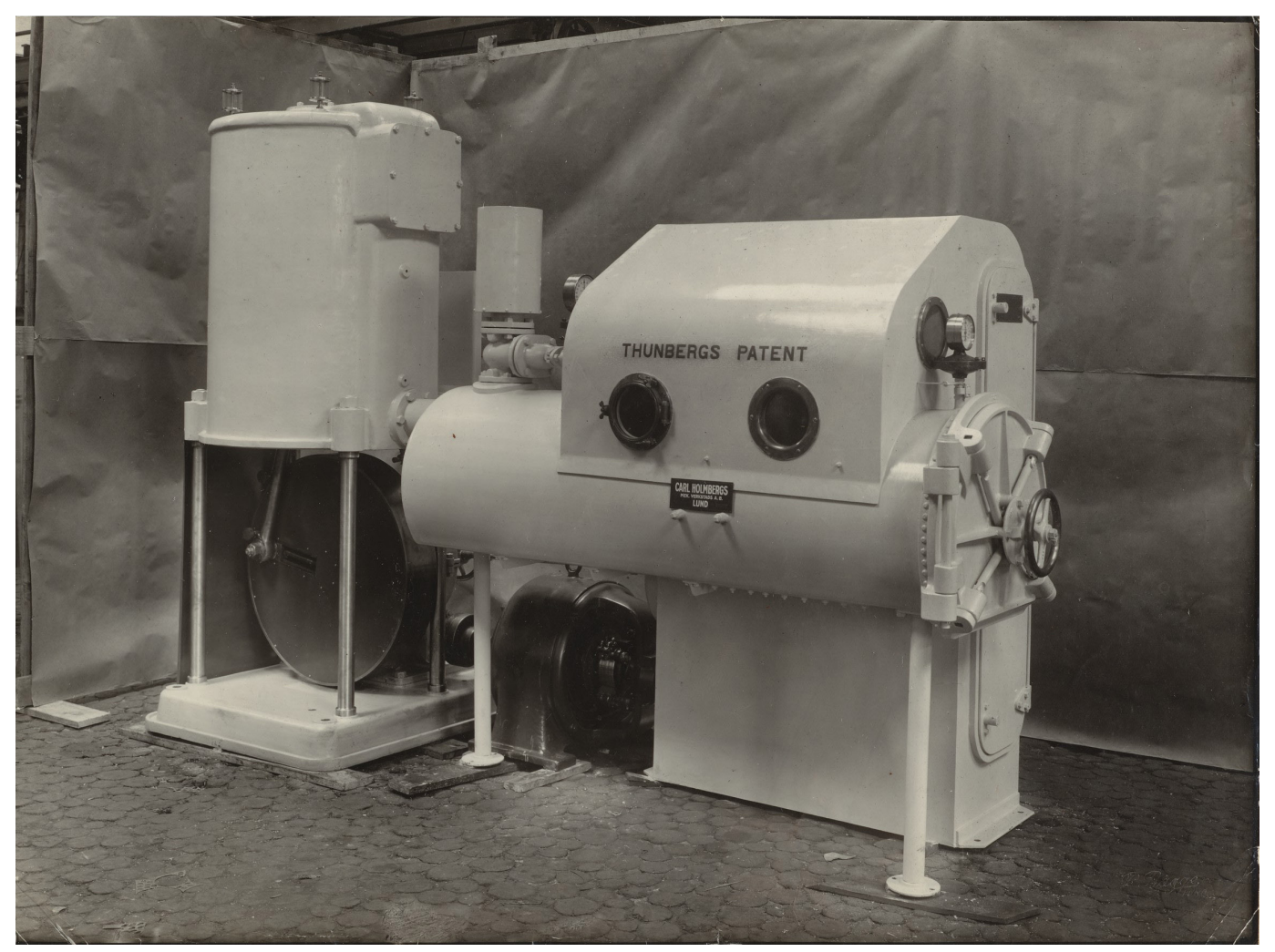

Figure 2 - Thunberg barospirator in Petrén's clinic at Lund, Sweden.

Benedict, "Reports of Visits to Foreign Laboratories," Francis A. Countway Library of Medicine. Center for the History of Medicine, Harvard University. Public domain. 


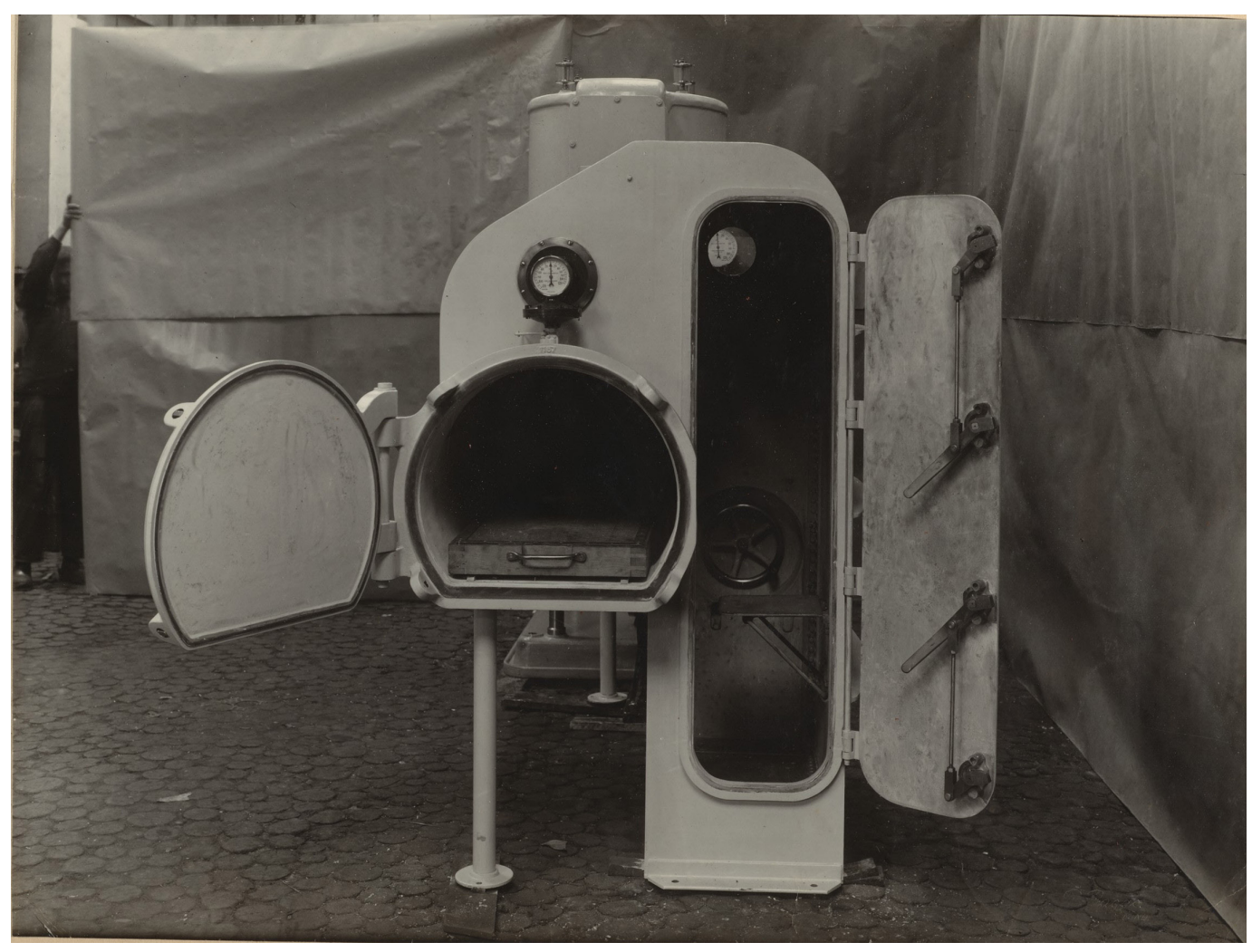

Figure 3 - Lateral view

Benedict, "Reports of Visits to Foreign Laboratories," Francis A. Countway Library of Medicine. Center for the History of Medicine, Harvard University. Public domain. 


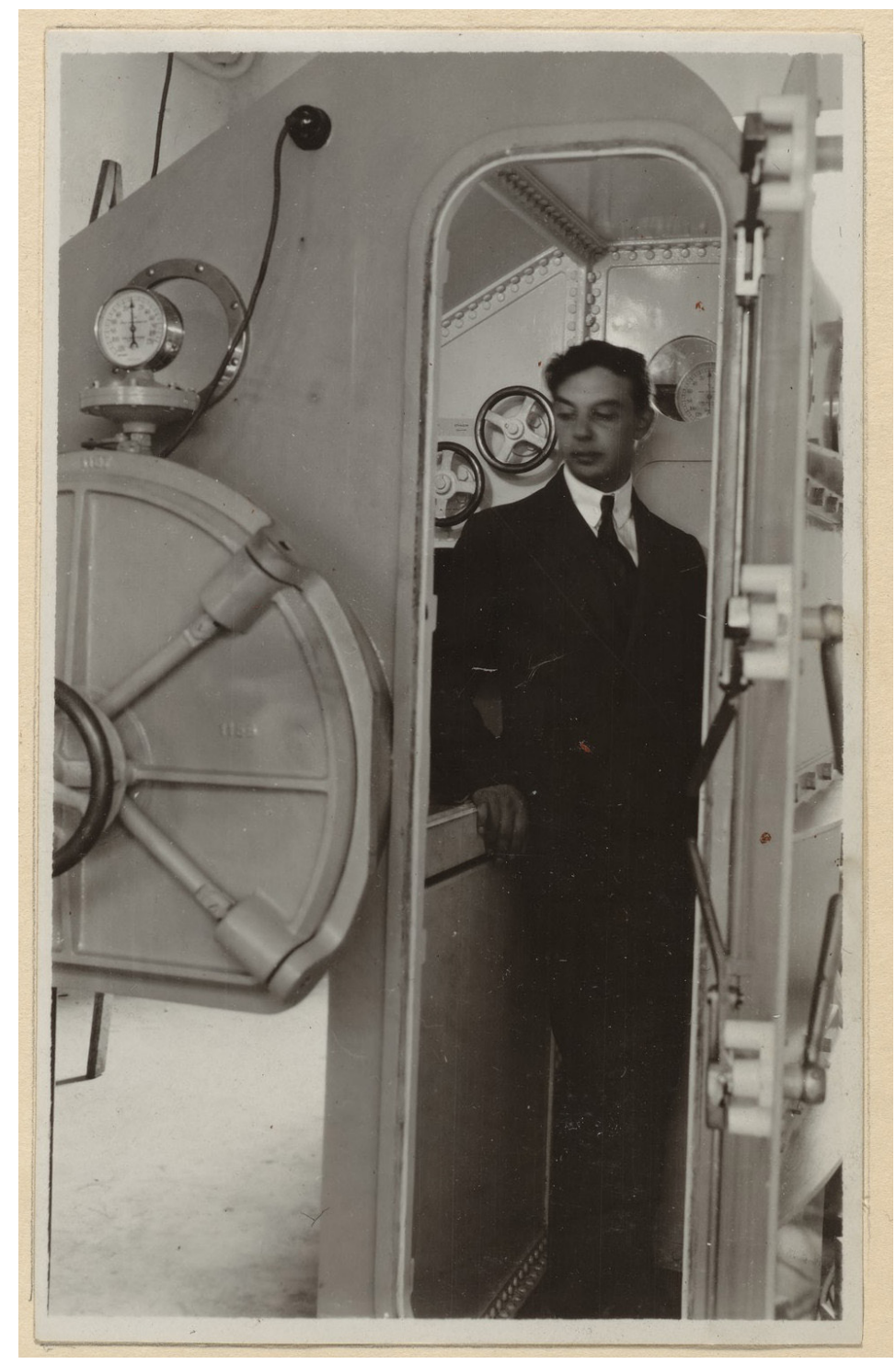

Figure 4 - Dr. Enghoff standing in the interior of the Thunberg barospirator in Petrén's clinic at Lund, Sweden.

Benedict, "Reports of Visits to Foreign Laboratories," Francis A. Countway Library of Medicine. Center for the History of Medicine, Harvard University. Public domain.

The idea of the Barospirator as a shareable space was, however, short-lived. This was firstly because the drive that led the investigation in early years had changed significantly. In 1932, Bo Carl Henrik Sahlin (1901-1949) — by then Thunberg's assistant at the Physiological Institute at the University of Lund - had successfully created a device to use the Barospirator as an 
artificial respiration apparatus, somehow against its original design. ${ }^{95}$ The main reference for the new design was Drinker's respirator, and the underlying idea was that its primary function was saving lives. Petrén died in 1927, and with him also passed the experimental and analytical drive that made him consider the machine "an extraordinarily bold attempt to intervene in the organisation of the organism by striving for what has previously never been achieved in the evolutionary history of higher animals and humans, to put the respiratory movements, this fundamental function of life, out of action." ${ }^{96}$ A machine for saving lives requires a different standardising regime than one for experimental purposes.

This was also the force behind Emerson's improvement of Drinker's respirator. He aimed at a cheaper, more accessible, less noisy, and more versatile tool. The production of his first prototype was precipitated by the imminence of the 1931 polio outbreak, and so Emerson resorted to ready-made shapes that could provide parts quickly and easily. This was what Drinker had done three years before. However, Emerson was able to identify more flexible substitutes for core parts of Drinker's design. For example, he resorted to a boiler manufacturer for the tank, which consequently became a cylinder. ${ }^{97}$ The choice shortened production time significantly. Opportunities to test his prototype soon came, as the shortage of Drinker respirators opened the doors to equivalents from other manufacturers. The chance of putting Emerson's machine to work in the same room as Drinker's also allowed for favourable comparisons: Emerson's was much less noisy. Moreover, on its first run at Rhode Island Hospital, Emerson's machine was successful: the patient recovered. ${ }^{98}$ This, along with his machine's significantly lower price, afforded Emerson wonderful publicity.

Urgency — medical emergency, but also economic competition-kept elemental modularity at the core of the machine's design. Even though a room-size respirator was produced in the 1930s and its many advantages for patients were highlighted, respirators were expected to be used on a seasonal basis, accordingly to the pattern of poliomyelitis epidemics. A stable massive infrastructure would interfere with the hospital's ecologic system, as it was the setting for multiple local diseases and conditions. Each condition enacted its environmental relationships accordingly to the many constrictions imposed by social and infrastructural synergies. Space, subjective appreciation of risk or improvement, joint demand for energy were all of them at stake. This meant that the unexpected adaptation of patients to the tank respirator-their long-term symbiosis with a microenvironment expected to be transitional-

95 Francis Gano Benedict, Reports of Visits to Foreign Laboratories, seven volumes, 1907-1933, volume 7, on p. 46, Series: II. Boston Nutrition Laboratory Records, 1904-1954, Francis A. Countway Library of Medicine.

96 Pétren and Sjövall, “Eine Studio,” 269.

97 John Haven Emerson, "Some Reflections on Iron Lungs and Other Inventions," Respiratory Care 43, no. 7 (1998): 573-584, on 574.

98 Ibid., 574. 
posed a new challenge that produced two solutions: more control over their relationship with the machine, and a more stable presence in the hospital through the creation of intensive care unities. Certainly, improvements in intensive nursing improved iron lung efficiency, but nursing protocols were also dictated sharply by the conceptual and practical challenges posed by this specific technology.

\section{Conclusions}

The cases analysed above ended in a similar way. Birds as well as patients become residual: their fluctuant and complex nature is evidenced in the process of becoming de-coupled from a specific material environment and entering a contested mode of existence-as non-easily re-coupled to previous standards and physical agents. The efforts to keep these bodies linked together to well established codes and expected cartographies make their unfolding beyond the narrow limits of human experience more conspicuous. What is being preserved, then, is also beyond the re-establishment of a function: it is not the breathing but the appropriate or stabilised way of breathing, the one that fits smoothly with other cultural, material, and economic thresholds. Stabilising a kind of entity requires, as noted, sustained de-contextualising but also sanctioning of suitable environments; dis-placements to new uncharted environments challenge this stabilisation or appropriateness by imposing new functional arrangements, or ways of living. This brings a fork: making environment detachable and acknowledging it as place of residence.

As the case of birds shows us, preservation strategies are set in place partly in response to a moral demand, triggered by a cultural system, and partly as an effect of accidental technological failure. Failure that, also in the case of iron lungs, must be understood as the production of inhabited spaces characterised by uncertainty. These strategies or response paths have two dimensions. First, they propose the multiplication of environments: environment became scenarios. The scenic nature of the environment has to do with the second strategy: the way in which agents are transformed in steady homogenous presences, by way of being defined as sustained, detachable, and re-integrable parts. Interaction between them, hence, is overlooked and remain unexplained. For example, noise continuity allows a rhetoric of enclosurebirds being trapped in continuous noise-that generates an urgency for action. It impedes the consideration of how noise is linked to cohabitation and how new elements can become neighbours, or why different species succeed in dense infrastructural environments. It fails to provide a sense of how standards can be used to produce adjustable and varying tuning between species. In both cases the implementation of standards according to procedures that are progressively and contingently adjusted gives place to a long and slow adjustment with no definite ends. The technological density of such enterprise provides a type of continuity to some agents, putting an end to intermittent situations or fluctuating, plastic "modes of existence." 
Technological density means that the emergent production of standards, which is determined by the path of dependence produced by technological innovation, is a strong force that shapes the way we produce technological stability and arrange convenient relationships between different entities. However, preservation spaces always impose a change of rhythm, a change of texture, related to the new synchronisations required between the targeted agents and the new environment. Both birds in the CEZ and people in the iron lung are "produced" in two senses. First, by the technologies or machines that allow to produce virtual or physical perimeters based on specific thresholds. These include density of population, degree of radiation, minimal space to attain control on a constant and fast change of pressure, resistance of the perimetral material that holds this space. Second, by the cumulative, modular attachment of measurements or assemblages that help to give them a more precise shape. The codes do maintain the gap that marks the borders of the space produced this way, but they do not control the emerging internal grammar. This grammar results from interactions between internal agents, whose potentialities — to which codes are blind — are unleashed by their new proximity and the new ways of producing functional coupling. Moreover, the iron lung becomes a symbiotic part of the patient, as it no longer can be detached from the patient as mere scenario. This is how expectations are de-activated, since they only can work properly under the assumption that there is no consubstantial interaction between the target objects and the surrounding objects that conform the environment. Thus, these examples also demonstrate that the expectations created around the agents of a specific landscape (or infrastructural-scape) are important in hindering paths of inquiry towards potential forms of cohabitation.

Perimetric thresholds may or may not be inherent to the subject of standardisation, which is nestled there contingently. However, as the perimeter relates the individuals to inside/ outside, exclusion/inclusion, normal/pathological logics, variations in this perimeter might produce changes in the consideration of the beings dwelling inside its boundaries and on what dwelling or inhabiting consists.

As shown, these changes have less to do with interpretations than to intimacy and synchronisation; the active coupling between noise and birds, or people and positive/negative pressures tend to produce new kinds of stabilisations. Resistance on the part of standardised procedures takes shape as such couplings are harnessed and hindered by expressive dimensions that evaluates cultural and economic adjustments accordingly to a set of categories or incorporeal transformations (autonomy, rentability, efficiency, dignity). This is how the more comfortable the iron lung, the less courageous it is considered to be in there.

Time spent inside will be valued differently. In the case of the iron lung, the more porous or polymorphic the walls, and the more accessible to other's hands, the less the patient is expected to define his or her own limits and (be)longings, and become more unstable. The iron lung was successively claimed as a space of salvation and hope, as well as a space of damnation. The 
same is true of the CEZ. Success in being one with the artificial environment is alternatively applauded and rejected. This is inherent to transitional or liminal spaces. Moreover, this intermittency is related to the possibility of measuring, cataloguing, and achieving some stability in successive discontinuous episodes. In specific cases, what provides the rationale for generalisations and ontological robustness is precisely the definition of a microenvironment that stabilises a condition or way of being. That is what preservation is about. However, it imposes a fracture between experience and ontological stabilisation, and this tension requires an exploration of the frailty of the actors involved. It is this frailty, this indetermination, that keeps the microenvironment in a dynamic state: birds explore unexperienced pitches, frequencies, ranges of their "active space"; people attempt synchronisation with machines, ways of communication, and alternative meanings to "feel at home."

Producing standards for living beings that inhabit a space that is not shareable, and that is pervaded by historically incongruous data, instruments, practices, memories, and technoscapes adds new challenges. Remote monitoring is not a new practice. Astrophysicists have long since produced a narrative in which astral bodies acquire volume, position, and area of influence through the establishment of standardised measurements of light and heat spectra. Applying similar technology to contemporary, co-space and co-scalar entities is, however, uncanny. It transforms our notions of cohabitation radically.

The modular style of adjusting standards emergently is different to the process of standardisation for something like a screw, for example. In this case, the screw's limits are known beforehand; to define these is a known, exhaustible, and attainable target. It is not that the one style displaces the other: the enormous work of synchronisation of forms of stabilisation of languages, production of instruments, formation of practices and abilities, and maintenance of ontological coherence that go with nestled processes of standardisation incorporates several possible styles. We must necessarily rely on layers of information, but when our concerns are preservation of ontological diversity, protection against biological extinction, fractures, and time decalage between data production and data processing - as astrophysicists well know-do matter. We experience the light of stars that vanished long ago. In the two analysed cases this fracture is conspicuous, but the analysis also points to a path of growing indeterminacy of the object of standardisation, and a weakening of ontological continuities. The question to ask is no longer "Are you there?" but maybe "Who is there?" A more poignant question we must ask ourselves is if we are readyand what it might mean - to cohabit with more blurred and spectral presences. These extended ways of cohabitation that sustain social forms of interaction considered to be essential for an integral concept of living-being and humanity, will still be shaped by standardised ways of contouring spaces and entities. However, in any case, awareness about fabricated extinction or artificial continuity would require us to rework our relationship with our world-mates.

Many of the contradictory dynamics outlined here are now becoming familiar from the 
experience of domestic confinement decreed in many countries because of the COVID-19 pandemic. People are being confined to prevent them from becoming machines for spreading the virus. It is in this capacity that they are disconnected from an environment that is supposed to be occupied, colonised by a threatening entity, dissolving the status quo of the general environment. A background of precarity and limitations in health infrastructures constitutes a scenario of selection of relevant interactions on which the very precariousness of the confined bodies is built. This scenario is proposed as a transitory event. At the same time, the "return" to the house in these conditions does not constitute a return to a known place but to a space in which new futures and conditions, are elaborated. Redefining a security perimeter involves redistributing enormous amounts of energy. Not only new forms of precariousness — economic and emotional- manifest themselves in the suspension of the interactions of a stable environment, but also alternatives to needs and, consequently, to modes of living. It is not yet clear what kind of consequences current strategies for tracking people's behavior during confinement using AI devices will have. Technological shortcomings and moral concerns about resource consumption and information management for this purpose remain crucial. But the bifurcation between coded presences and modes of existence, and the reversal and change of notions of external/internal, open/closed environments will undoubtedly produce new types of autonomy. Threatening or not, future travel companions and as yet undefined alliances are on the way to becoming.

\section{Competing Interests}

The author has declared that no competing interests exist.

\section{Funding}

This work has been supported by the projects: "Material cultures, epistemic cultures. Standards, cognitive processes and knowledge" (State Plan ICyT-i, FFI2013-45659-R), directed by Jesús Vega Encabo (UAM, Madrid); "Exploration of Non-Anthropocentric Relational Creativity" (CONACYT, Basic Sciences, A1-S-21700, 2019-2021), directed by Nuria Valverde Pérez (UAM-C, CDMX). 